\title{
Clinical validity of endoscopic submucosal dissection for submucosal invasive gastric cancer: a single-center study
}

\author{
Yoji Sanomura $\cdot$ Shiro Oka $\cdot$ Shinji Tanaka Ikue Noda $\cdot$ Makoto Higashiyama \\ Hiroki Imagawa $\cdot$ Takayoshi Shishido $\cdot$ Shigeto Yoshida $\cdot$ Toru Hiyama $•$ \\ Koji Arihiro • Kazuaki Chayama
}

Received: 19 April 2011 / Accepted: 26 June 2011/Published online: 23 July 2011

(C) The International Gastric Cancer Association and The Japanese Gastric Cancer Association 2011

\begin{abstract}
Background The 2010 Japanese Gastric Cancer Association guidelines for the treatment of submucosal invasive gastric cancer (SM-GC) specify size $30 \mathrm{~mm}$ or less, differentiated-dominant histology, lack of vessel involvement, and submucosal invasion of less than $500 \mu \mathrm{m}$ (SM1) as expanded criteria for curative endoscopic resection. Our purpose in this study was to confirm the validity of the expanded indications for curative endoscopic submucosal dissection (ESD) of SM-GC.

Methods The study subjects were 173 patients with SMGC resected by ESD at Hiroshima University Hospital between April 2002 and September 2010, including 99 patients for whom 3-plus years' follow-up information was available. Post-ESD outcomes were compared between cases of SM1-GC that met the expanded ESD criteria, those that did not, and SM2-GC cases.
\end{abstract}

Y. Sanomura $\cdot$ I. Noda $\cdot$ M. Higashiyama $\cdot$ H. Imagawa $\cdot$

T. Shishido $\cdot$ K. Chayama

Department of Medicine and Molecular Science,

Hiroshima University Graduate School of Biomedical Science,

1-2-3 Kasumi, Minami-ku, Hiroshima 734-8551, Japan

S. Oka $(\bowtie) \cdot$ S. Tanaka $\cdot$ S. Yoshida

Department of Endoscopy, Hiroshima University Hospital,

1-2-3 Kasumi, Minami-ku, Hiroshima 734-8551, Japan

e-mail: oka4683@hiroshima-u.ac.jp

T. Hiyama

Health Service Center, Hiroshima University,

1-7-1 Kagamiyama, Higashihiroshima 739-8514, Japan

K. Arihiro

Department of Pathology, Hiroshima University Hospital,

1-2-3 Kasumi, Minami-ku, Hiroshima 734-8551, Japan
Results Complete resection was achieved for $93.2 \%$ of the SM1-GCs that met the expanded criteria. There was neither metastasis to lymph nodes or other organs nor local recurrence among the SM1-GCs. Disease-specific survival did not differ significantly between patients that were simply followed up after ESD and those that were treated by additional surgical resection.

Conclusions Our outcome data support the clinical validity of ESD without additional surgical resection for SM1-GCs that meet the expanded criteria.

Keywords ESD - Submucosal invasive gastric cancer . Prognosis

\section{Introduction}

Early gastric cancer (EGC) is defined as tumor invasion confined to the mucosa or submucosa, irrespective of whether lymph node metastasis is present. The Japanese classification of gastric carcinoma issued by the Japanese Gastric Cancer Association (JGCA) defines submucosal invasion of less than $500 \mu \mathrm{m}$ as SM1 and that of $500 \mu \mathrm{m}$ or more as SM2 [1].

Endoscopic submucosal dissection (ESD) is an established treatment method in Japan that does not rely on snare techniques for the dissection of submucosal tissue and allows en-bloc resection of even large EGCs [2-6]. Moreover, submucosal tissue can be resected with sufficient vertical distance from the muscularis mucosae. Thus, ESD allows precise histologic assessment of the resected specimen and may prevent local recurrence.

Gotoda et al. [7] summarized data from 2 very large centers and reported that ECGs $30 \mathrm{~mm}$ or less in diameter, with differentiated-dominant histology, lack of vessel 
involvement, and submucosal invasion of less than $500 \mu \mathrm{m}$ were entirely free of lymph node metastasis. Therefore, according to the JGCA treatment guidelines [8], this subgroup of submucosal invasive gastric cancers (SM-GCs) can be followed up without additional surgical resection. Five-year disease-specific survival has been achieved in $96.8 \%$ of patients with SM-GCs treated by surgical resection [9]. However, the prognosis in patients with SM-GCs treated by ESD remains unspecified, and the actual feasibility of ESD for SM-GCs remains controversial. To our knowledge, although outcomes of EGCs resected by ESD have been reported [10-17], there are no reported comparisons between SM1-GC and SM2-GC. Therefore, we studied outcomes in patients with SM-GCs treated by ESD to determine the feasibility of the procedure across classifications.

\section{Patients and methods}

\section{Patients}

A total of 173 patients with 173 SM-GCs were treated by ESD at Hiroshima University Hospital between April 2002 and September 2010. Upon pathologic examination, the lesions were classified as follows: those $30 \mathrm{~mm}$ or less in diameter, with differentiated-dominant histology, lack of vessel involvement, and submucosal penetration of less than $500 \mu \mathrm{m}$ (i.e., meeting the expanded SM1 criteria, $n=59$ ); those with submucosal penetration of less than $500 \mu \mathrm{m}$ that did not meet the expanded SM1 criteria ( $n=31$ ); and those showing submucosal penetration of $500 \mu \mathrm{m}$ or more (SM2) [8]. In principle, we recommend that patients with an SM2 tumor or those with an SM1 tumor that does not meet the expanded criteria be treated by additional surgical resection. Written informed consent was obtained from all patients for ESD and for additional surgical resection if necessary.

\section{ESD procedure}

ESD was performed with the use of a single-channel endoscope (GIF-H260, -H260Z, or -Q260J; Olympus, Tokyo, Japan; or EG-450RD5; FUJIFILM Medical, Tokyo, Japan) or a 2-channel endoscope (GIF-2TQ260M; Olympus; or EG-450D5; FUJIFILM Medical). Several spots were marked by argon plasma coagulation 5-10 mm outside the margin of the cancer lesion. After the injection of $10 \%$ glycerin solution and 5\% fructose with $0.0025 \%$ epinephrine into the submucosa, an initial incision was made with a needle knife outside the line of spots. We used mainly an insulation tipped (IT) knife, IT knife2, or Hook knife (Olympus), which was then inserted into the initial incision, and electrosurgical current was applied with the use of an electrosurgical generator (ICC 200, VIO 300D; ERBE, Tubingen, Germany; or ESG-100; Olympus) to complete the circumferential mucosal incision around the lesion. An IT knife or IT knife2 was used to exfoliate the submucosa with coagulation current. Injection was repeated as needed, and further resection was carried out to ensure total removal of the lesion.

At the end of the ESD procedure, all exposed vessels on the artificial ulcer were coagulated with the use of hemostatic forceps (FD-410LR; Olympus; or HDB2418W-W; PENTAX, Tokyo, Japan). We consistently undertook second-look endoscopy on the day after ESD, and we coagulated all exposed vessels on the artificial ulcer regardless of whether bleeding was present [18, 19].

Bleeding after ESD was defined as bleeding manifested by a fall in the hemoglobin level of $2 \mathrm{~g} / \mathrm{dl}$ or more below the most recent preoperative level, observation of any bleeding source, or massive melena [20]. Perforation was diagnosed endoscopically just after resection or by the presence of free air on a plain abdominal radiograph or computed tomography image.

\section{Histopathologic examination}

Histopathologic examination was based on the 2010 Japanese classification of gastric carcinoma issued by the JGCA. The entire resected specimen was cut into 2-mmthick parallel sections and examined under hematoxylin and eosin staining for detailed analysis, including analysis of the deepest invasive portion containing infiltrating cancer cells. GCs are classified as differentiated or undifferentiated. The former type includes well-differentiated tubular adenocarcinoma, moderately differentiated tubular adenocarcinoma, and papillary adenocarcinoma; the latter includes poorly differentiated adenocarcinoma, signet ring cell carcinoma, and mucinous adenocarcinoma. En-bloc resection was defined as resection in a single piece. Complete resection was defined as the en-bloc resection of a tumor that was shown to be free of cancer cells at both the horizontal and vertical cut ends.

\section{Follow-up}

Follow-up endoscopic examinations for local recurrence were scheduled according to the type of resection. In patients who had had a complete resection, follow-up examination was done at 6 months after the procedure and once every 12 months thereafter; in patients who had had an incomplete resection, follow-up examination was done at 3 months after the procedure, 12 months after the procedure, and every 12 months thereafter. In addition, if deemed necessary, in patients who had had an incomplete 
resection, transabdominal ultrasonography and computed tomography were performed every 6 months after ESD. Biopsy specimens were taken from any ulcerative lesion identified during follow-up examinations to histologically confirm the presence of residual tumor or local recurrence.

\section{Evaluation of outcomes}

The following clinical variables were investigated: patient age, sex, tumor location, gross type, size, ulceration, dominant histologic type, histologic type of the deepest invasive portion, infiltration, lymphatic involvement, venous involvement, en-bloc resection rate, complete resection rate, positive vertical margin rate, delayed bleeding rate, perforation rate, and operation time.

For prognostic analysis, data obtained for 99 of the 173 patients were analyzed. The 99 patients represent $91.7 \%$ of the 108 patients with SM-GCs who were treated by ESD between April 2002 and September 2007. In other words, considerable time had passed since the ESD, so 3-year survival, death, and recurrence rates could be analyzed. We analyzed overall and disease-specific survival rates for each of the following: SM-GCs treated by additional surgical resection after ESD, SM1-GCs that met the expanded criteria and were simply followed up after ESD, SM1-GCs that did not meet the expanded criteria and were simply
Table 1 Clinicopathologic features of submucosal invasive gastric cancers resected by ESD

$E S D$ endoscopic submucosal dissection, expanded SMI criteria submucosal invasive gastric cancer $30 \mathrm{~mm}$ or less in diameter, with differentiateddominant histology, lack of vessel involvement, and submucosal penetration of less than $500 \mu \mathrm{m}$, infiltration a tumor shows expanding growth and a distinct border in relation to surrounding tissue, infiltration $b$ tumor

characteristics between those of infiltration a and infiltration c, infiltration $c$ tumor shows infiltrating growth and an indistinct border in relation to surrounding tissue

\begin{tabular}{|c|c|c|c|c|}
\hline \multirow[t]{2}{*}{ Variable } & \multicolumn{2}{|l|}{ SM1 } & \multirow[t]{2}{*}{$\operatorname{SM} 2(n=83)$} & \multirow[t]{2}{*}{ Total $(n=173)$} \\
\hline & $\begin{array}{l}\text { Expanded criteria } \\
\text { met }(n=59)\end{array}$ & $\begin{array}{l}\text { Criteria not } \\
\text { met }(n=31)\end{array}$ & & \\
\hline Patient age (years) & $69.3 \pm 7.9$ & $71.2 \pm 8.8$ & $71.8 \pm 10.6$ & $70.8 \pm 9.5$ \\
\hline Sex ratio $(\mathrm{M} / \mathrm{F})$ & $53 / 6$ & $23 / 8$ & $62 / 21$ & $138 / 35$ \\
\hline \multicolumn{5}{|l|}{ Tumor location } \\
\hline Upper & 18 & 6 & 22 & 46 \\
\hline Middle & 16 & 16 & 21 & 53 \\
\hline Lower & 24 & 9 & 39 & 72 \\
\hline Remnant & 1 & 0 & 1 & 2 \\
\hline \multicolumn{5}{|l|}{ Gross type } \\
\hline Depressed & 47 & 24 & 54 & 125 \\
\hline Non-depressed & 12 & 7 & 29 & 48 \\
\hline \multicolumn{5}{|l|}{ Size } \\
\hline$\leq 30 \mathrm{~mm}$ & 59 & 14 & 67 & 140 \\
\hline$>30 \mathrm{~mm}$ & 0 & 17 & 16 & 33 \\
\hline \multicolumn{5}{|l|}{ Ulceration } \\
\hline Present & 13 & 18 & 26 & 57 \\
\hline Absent & 46 & 13 & 57 & 116 \\
\hline \multicolumn{5}{|l|}{ Histology (dominant) } \\
\hline Differentiated & 59 & 24 & 69 & 152 \\
\hline Undifferentiated & 0 & 7 & 14 & 21 \\
\hline \multicolumn{5}{|c|}{ Histology at the deepest invasive portion } \\
\hline Differentiated & 59 & 21 & 58 & 138 \\
\hline Undifferentiated & 0 & 10 & 25 & 35 \\
\hline \multicolumn{5}{|l|}{ Infiltration } \\
\hline $\mathrm{a}$ & 15 & 9 & 13 & 37 \\
\hline $\mathrm{b} / \mathrm{c}$ & 44 & 22 & 70 & 136 \\
\hline \multicolumn{5}{|c|}{ Lymphatic involvement } \\
\hline Present & 0 & 5 & 19 & 24 \\
\hline Absent & 59 & 26 & 64 & 149 \\
\hline \multicolumn{5}{|l|}{ Venous involvement } \\
\hline Present & 0 & 2 & 7 & 9 \\
\hline Absent & 59 & 29 & 76 & 164 \\
\hline
\end{tabular}


followed up after ESD, and SM2-GCs that were simply followed up after ESD.

Statistical analysis

Quantitative data are expressed as means and standard deviation (SD) or percentages. Differences in values were analyzed by the $\chi^{2}$ test with Yates correction or by Student's $t$-test. Kaplan-Meier survival curves were drawn, and Cox proportional hazards modeling and log-rank test were used for analysis of survival. Differences at $p<0.05$ were considered statistically significant.

\section{Results}

Clinicopathologic variables

The clinicopathologic features of the 173 study patients are shown in Table 1. There were no between-group differences in patient age, sex, tumor location, gross type, ulceration, or infiltration. Overall, 152 of the SM-GCs were of the differentiated type, and 21 were of the undifferentiated type. Histologic examination of the deepest invasive portion revealed differentiation in 138 cases and non-differentiation in 35. Lymphatic involvement was found in 24 cases, and venous involvement was found in 36 .
Clinical outcomes of ESD for SM-GCs

The outcomes of the ESDs are shown in Table 2. The enbloc resection rate did not differ significantly between tumors that met the expanded SM1 criteria (93.2\%), tumors that did not meet the expanded SM1 criteria (80.6\%), and SM2 tumors $(84.3 \%)$. However, the complete resection rate was significantly better for tumors that met the expanded SM1 criteria $(93.2 \%)$ than for those that did not meet the expanded SM1 criteria $(74.2 \%)$ or for the SM2 tumors $(57.8 \%)$. The positive vertical margin rate was significantly higher for the SM2 tumors $(30.1 \%)$ than for those that met the expanded SM1 criteria $(0 \%)$ and for those that did not meet the expanded SM1 criteria (3.2\%). There was no statistically significant difference between the 3 groups in delayed bleeding rate, perforation rate, or operation time.

Outcomes of ESD in relation to ulceration are shown in Table 3 . The en-bloc resection rate and complete resection rate in patients with SM1-GCs were significantly higher for tumors without ulceration (96.6 and 94.9\%, respectively) than for tumors with ulceration $(74.2$ and $71.0 \%$, respectively). The vertical margin was positive in $1.1 \%$ (1/90) of SM1-GC cases and 30.1\% (25/83) of SM2-GC cases $(p<0.01)$, and it was positive in a significantly greater percentage of SM2-GCs with ulceration (52.0\%) than in those without ulceration $(20.7 \%)$. The average depth of SM2 lesions with a positive vertical margin was $1529 \mu \mathrm{m}$.
Table 2 Outcomes of ESD of submucosal invasive gastric cancers

$V M$ vertical margin

\begin{tabular}{lllll}
\hline Variable & SM1 & SM2 $(n=83)$ & $p$ value \\
\cline { 2 - 3 } & $\begin{array}{l}\text { Expanded criteria } \\
\text { met }(n=59)\end{array}$ & $\begin{array}{l}\text { Criteria not } \\
\text { met }(n=31)\end{array}$ & & \\
\hline En-bloc resection & $93.2 \%(55 / 59)$ & $80.6 \%(25 / 31)$ & $84.3 \%(70 / 83)$ & 0.1683 \\
Complete resection & $93.2 \%(55 / 59)$ & $74.2 \%(23 / 31)$ & $57.8 \%(48 / 83)$ & 0.0000 \\
VM-positive & $0 \%(0 / 59)$ & $3.2 \%(1 / 31)$ & $30.1 \%(25 / 83)$ & 0.0000 \\
Delayed bleeding & $3.4 \%(2 / 59)$ & $6.5 \%(2 / 31)$ & $6.0 \%(5 / 83)$ & 0.7241 \\
Perforation & $5.1 \%(3 / 59)$ & $3.2 \%(1 / 31)$ & $7.2 \%(6 / 83)$ & 0.6735 \\
Operation time $(\min )$ & $74 \pm 44$ & $120 \pm 95$ & $107 \pm 104$ & 0.061 \\
\hline
\end{tabular}

Table 3 Outcomes of ESD according to the presence of ulceration

\begin{tabular}{|c|c|c|c|c|}
\hline \multirow[t]{2}{*}{ Variable } & \multicolumn{2}{|l|}{ SM1 $(n=90)$} & \multicolumn{2}{|l|}{$\operatorname{SM} 2(n=83)$} \\
\hline & $\mathrm{UL}(-)(n=59)$ & $\mathrm{UL}(+)(n=31)$ & $\mathrm{UL}(-)(n=58)$ & $\mathrm{UL}(+)(n=25)$ \\
\hline En-bloc resection & $96.6 \%(57 / 59)^{\mathrm{a}}$ & $74.2 \%(23 / 31)^{\mathrm{b}}$ & $89.7 \%(52 / 58)$ & $72.0 \%(18 / 25)$ \\
\hline Complete resection & $94.9 \%(56 / 59)^{\mathrm{a}}$ & $71.0 \%(22 / 31)^{\mathrm{b}}$ & $65.5 \%(38 / 83)$ & $40.0 \%(10 / 25)$ \\
\hline VM-positive & $0 \%(0 / 59)$ & $3.2 \%(1 / 31)$ & $20.7 \%(12 / 58)^{\mathrm{a}}$ & $52.0 \%(13 / 25)^{\mathrm{b}}$ \\
\hline Operation time (min) & $74 \pm 47^{\mathrm{c}}$ & $121 \pm 69^{\mathrm{d}}$ & $80 \pm 53^{\mathrm{a}}$ & $168 \pm 104^{\mathrm{b}}$ \\
\hline
\end{tabular}

$V M$ vertical margin, $U L$ ulceration

a vs. b: $p<0.01$

c vs. d: $p<0.05$ 
Operation time was significantly shorter for SM2 tumors without ulceration than for those with ulceration.

\section{Survival outcomes after ESD for SM-GCs}

The clinicopathologic features of the 99 patients for whom survival data were analyzed are shown in Table 4. Of the 99 patients, 41 had a tumor that met the expanded SM1 criteria. Eight of these patients were treated by additional surgical resection after ESD. Thirteen of the 99 patients had an SM1 tumor that did not meet the expanded criteria. Of these patients, 6 were treated by additional surgical resection after ESD. Forty-five patients had an SM2 tumor;
28 of these patients were treated by additional surgical resection after ESD. Additional surgical resection was performed for $25.9 \%$ (14/54) of the SM1-GCs (average follow-up period, 52.4 months); however, there was no lymph node metastasis in any of these patients. There was also no recurrence of any of the 40 SM1-GCs that were not treated by additional surgical resection after ESD (average follow-up period, 51.2 months).

Additional surgical resection was performed for $62.2 \%$ (28/45) of the SM2-GCs (average follow-up period, 56.1 months); lymph node metastasis was observed in 2 of these patients, and 2 patients had residual submucosal invasion. One of the 2 patients with lymph node metastasis
Table 4 Clinicopathologic features of the 99 patients for whom survival data were analyzed

Expanded SM1 criteria submucosal invasive gastric cancer $30 \mathrm{~mm}$ or less in diameter, with differentiateddominant histology, lack of vessel involvement, and submucosal penetration of less than $500 \mu \mathrm{m}$, infiltration a tumor shows expanding growth and a distinct border in relation to surrounding tissue, infiltration $b$ tumor

characteristics between those of infiltration a and infiltration c, infiltration $c$ tumor shows infiltrating growth and an indistinct border in relation to surrounding tissue

\begin{tabular}{|c|c|c|c|c|}
\hline Variable & $\begin{array}{l}\text { SM-GCs treated by } \\
\text { additional surgical } \\
\text { resection after ESD } \\
(n=42)\end{array}$ & $\begin{array}{l}\text { SM1-GCs meeting the } \\
\text { expanded criteria and } \\
\text { followed up after ESD } \\
(n=33)\end{array}$ & $\begin{array}{l}\text { SM1-GCs not meeting } \\
\text { the expanded criteria } \\
\text { and followed up after } \\
\text { ESD }(n=7)\end{array}$ & $\begin{array}{l}\text { SM2-GCs } \\
\text { followed up } \\
\text { after ESD } \\
(n=17)\end{array}$ \\
\hline $\begin{array}{l}\text { Patient age } \\
\text { (years) }\end{array}$ & $68.1 \pm 9.3$ & $68.9 \pm 7.8$ & $74.2 \pm 7.5$ & $77.1 \pm 7.4$ \\
\hline Sex ratio $(M / F)$ & $34 / 8$ & $29 / 4$ & $3 / 4$ & $12 / 5$ \\
\hline \multicolumn{5}{|l|}{ Tumor location } \\
\hline Upper & 11 & 7 & 1 & 3 \\
\hline Middle & 14 & 11 & 3 & 3 \\
\hline Lower & 17 & 14 & 3 & 11 \\
\hline Remnant & 0 & 1 & 0 & 0 \\
\hline \multicolumn{5}{|l|}{ Gross type } \\
\hline Depressed & 30 & 22 & 5 & 9 \\
\hline Non-depressed & 12 & 11 & 2 & 8 \\
\hline \multicolumn{5}{|l|}{ Size } \\
\hline$\leq 30 \mathrm{~mm}$ & 32 & 33 & 2 & 14 \\
\hline$>30 \mathrm{~mm}$ & 10 & 0 & 5 & 3 \\
\hline \multicolumn{5}{|l|}{ Ulceration } \\
\hline Present & 15 & 6 & 1 & 4 \\
\hline Absent & 27 & 27 & 6 & 13 \\
\hline \multicolumn{5}{|c|}{ Histology (dominant) } \\
\hline Differentiated & 34 & 33 & 5 & 14 \\
\hline Undifferentiated & 8 & 0 & 2 & 3 \\
\hline \multicolumn{5}{|c|}{ Histology at the deepest invasive portion } \\
\hline Differentiated & 30 & 33 & 5 & 12 \\
\hline Undifferentiated & 12 & 0 & 2 & 5 \\
\hline \multicolumn{5}{|l|}{ Infiltration } \\
\hline $\mathrm{a}$ & 1 & 5 & 0 & 3 \\
\hline $\mathrm{b} / \mathrm{c}$ & 41 & 28 & 7 & 14 \\
\hline \multicolumn{5}{|c|}{ Lymphatic involvement } \\
\hline Present & 7 & 0 & 0 & 4 \\
\hline Absent & 35 & 33 & 7 & 13 \\
\hline \multicolumn{5}{|c|}{ Venous involvement } \\
\hline Present & 3 & 0 & 0 & 3 \\
\hline Absent & 39 & 33 & 7 & 14 \\
\hline
\end{tabular}




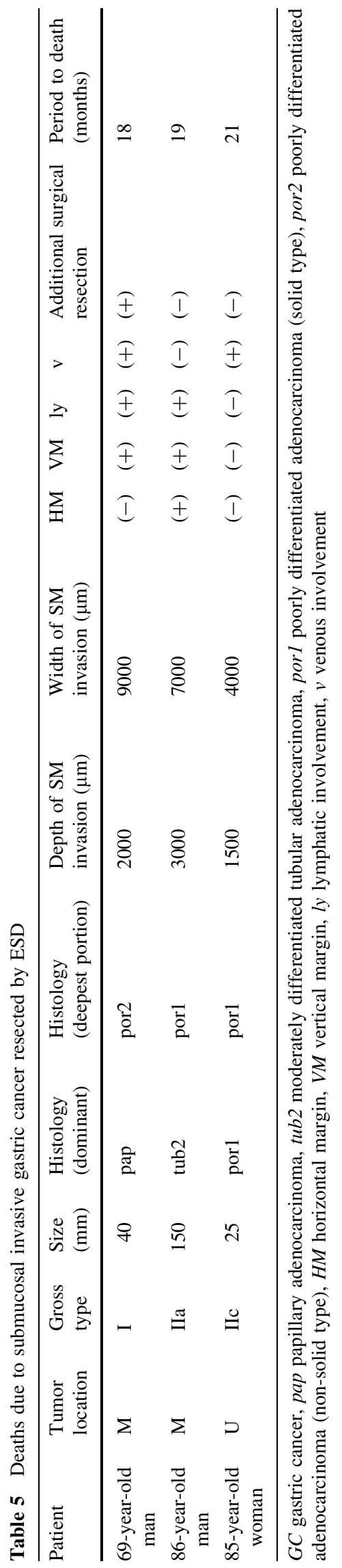

died of the primary disease. Of the 17 patients not treated by additional surgical resection, 2 patients of advanced age refused additional surgical resection and died of the primary disease (Table 5). Kaplan-Meier estimates of overall survival are shown in Fig. 1. According to the log-rank test, the overall survival of patients who were followed up after ESD without additional surgical resection was significantly lower than that of patients in the other 3 groups. Disease-specific survival rates did not differ significantly between any of the 4 groups (Fig. 2). The hazard ratios for the overall and disease-specific survivals in patients with SM2-GC followed up after ESD compared with those in patients with SM1-GC followed up after ESD or with SMGC treated by additional surgical resection after ESD were 13.40 and 12.54 , respectively (Table 6).

\section{Discussion}

Among our study patients, complete resection was achieved in $93.2 \%$ of cases that met the expanded criteria for SM1-GC proposed by Gotoda et al. [7]. The outcomes for SM1-GCs that met the expanded criteria and were simply followed up after ESD were equally as good as those for SM-GCs treated by additional surgical resection after ESD.

We have reported the usefulness of ESD versus endoscopic mucosal resection for complete resection of EGC [2, 21]. ESD makes complete resection possible regardless of tumor size or location. However, the en-bloc resection rate appears to be significantly lower for lesions with ulceration than for those without. In our patient series, complete resection was achieved for significantly fewer SM1-GCs with ulceration than for SM1-GCs without ulceration. In addition, operation time was significantly shorter for SMGCs without ulceration than for SM-GCs with ulceration. Further studies are needed to develop new ESD techniques and devices to overcome the technical difficulties associated with ulceration.

Although some investigators have reported that a pretreatment determination of whether submucosal invasion exceeds $500 \mu \mathrm{m}$ is difficult to achieve [22, 23], we have reported that a depth of submucosal invasion of up to $1000 \mu \mathrm{m}$ can be established by means of endoscopic ultrasound [24]. ESD allows submucosal tissue to be resected with sufficient vertical distance from the muscularis mucosae. Therefore, precise pathologic examination of the deepest invasive portion becomes possible with ESD. Thus, ESD serves not only as a therapeutic procedure but also ensures total incisional biopsy.

The probability of lymph node metastasis ranges from 10.2 to $22.9 \%$ in cases of SM-GC [25-29]. As we reported previously [30], when examining SM-GCs, it is important 
to take into account the histologic type of the deepest invasive portion in addition to the main histologic type. Hanaoka et al. [31] reported that, in SM-GCs of mixed differentiated and undifferentiated types, the undifferentiated-type-predominant mixed-type showed a significantly higher incidence of lymph node metastasis with a significantly greater depth of submucosal invasion compared to the differentiated type. Further, we have reported

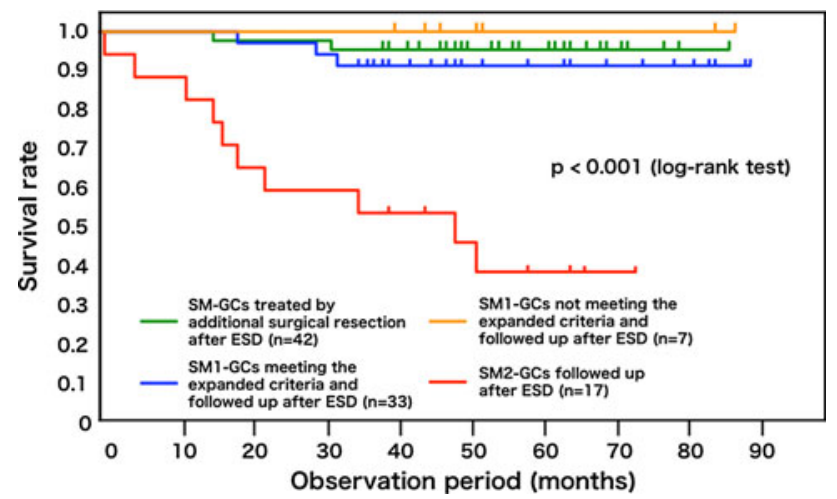

Fig. 1 Kaplan-Meier analysis of overall survival in patients with submucosal invasive gastric cancer $(S M-G C)$ treated by endoscopic submucosal dissection $(E S D)$

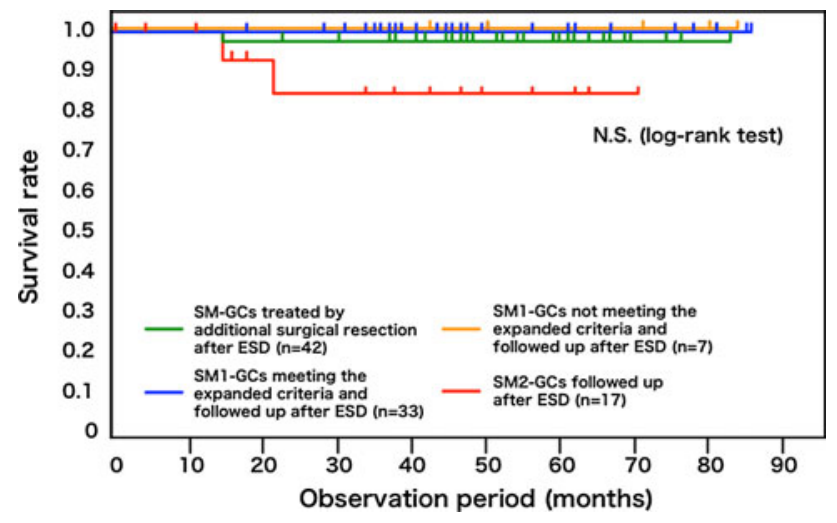

Fig. 2 Kaplan-Meier analysis of disease-specific survival of patients with submucosal invasive gastric cancer $(S M-G C)$ treated by endoscopic submucosal dissection (ESD). N.S. not significant that one of the independent risk factors for lymph node metastasis of SM-GC is the undifferentiated type at the deepest invasive portion [32]. Thus, examining the submucosal invasive portion is quite important for predicting lymph node metastasis.

In reporting outcomes of ESD for EGCs [10-17], Goto et al. [10] noted 5-year overall and disease-specific survival rates of 96.2 and $100 \%$, respectively, with neither lymph node metastasis nor other-organ metastasis. Gotoda et al. [11] found no significant difference in overall survival between EGCs that met the guideline criteria and those that met the expanded criteria. However, long-term outcomes for SM1-GCs vs. SM2-GCs have not been reported. Examination of overall survival in our patient series revealed high survival rates for patients with SM-GCs treated by additional surgical resection after ESD, those with SM1-GCs that met the expanded criteria and were simply followed up after ESD, and those with SM1-GCs that did not meet the expanded criteria but were simply followed up after ESD, although the overall survival rate of patients with SM2-GCs followed up after ESD was lower than that of the other patients. The overall survival rate of patients with SM2-GCs was low; however, 11 of the 17 patients with SM2-GCs that were simply followed up after ESD could not be treated by additional surgical resection because of advanced age or the presence of another disease. Consequently, 8 patients $(47.1 \%)$ with SM2-GCs followed up after ESD died of concomitant disease. Thus, it is quite difficult to compare survival between patients with SM-GCs not treated by additional surgical resection and those with SM-GCs treated by additional surgical resection. In terms of disease-specific survival, there was no statistically significant difference between any of our groups. Statistical interpretation of our results, however, is limited by the fact that our study included only a small number of patients from one institution and the follow-up period was not exceptionally long. In addition, the SM2GCs had been endoscopically diagnosed as indications for ESD, resulting in a possible selection bias.

We have previously reported independent risk factors for lymph node metastasis of submucosally invasive GCs to include the following: width of submucosal invasion

Table 6 Hazard ratios for overall and disease-specific survivals in each study group

\begin{tabular}{|c|c|c|c|c|}
\hline \multirow[t]{2}{*}{ Variable } & \multicolumn{2}{|c|}{ Overall survival } & \multicolumn{2}{|c|}{$\begin{array}{l}\text { Disease-specific } \\
\text { survival }\end{array}$} \\
\hline & $\begin{array}{l}\text { No. of } \\
\text { deaths }\end{array}$ & $\begin{array}{l}\text { Hazard } \\
\text { ratio }\end{array}$ & $\begin{array}{l}\text { No. of } \\
\text { deaths }\end{array}$ & $\begin{array}{l}\text { Hazard } \\
\text { ratio }\end{array}$ \\
\hline $\begin{array}{l}\text { SM1-GCs meeting the expanded criteria and followed up after ESD }(n=33)+\text { SM1-GCs not } \\
\text { meeting the expanded criteria and followed up after ESD }(n=7)+\text { SM-GCs treated by additional } \\
\text { surgical resection after ESD }(n=42)\end{array}$ & 5 & 1.00 & 1 & 1.00 \\
\hline SM2-GCs followed up after ESD $(n=17)$ & 10 & 13.40 & 2 & 12.54 \\
\hline
\end{tabular}


greater than $6000 \mu \mathrm{m}$, lymphatic involvement, undifferentiated type at the deepest invasive portion, depth of submucosal invasion greater than $1000 \mu \mathrm{m}$, and tumor diameter greater than $30 \mathrm{~mm}$ [32]. Although the limitations of our present study make broad generalization of our findings problematic, our data suggest that it may be possible to predict the absence of lymph node metastasis in cases of submucosal invasive GCs by evaluating these five risk factors in combination. Our present study involved 50 SM-GCs that satisfied these conditions. There was neither lymph node metastasis nor metastasis to another organ in any of these 50 cases.

In conclusion, our outcome data support the clinical validity of ESD without additional surgical resection for SM1-GCs of the differentiated type that are $30 \mathrm{~mm}$ or less in diameter and without vessel involvement. Moreover, our data suggest that it might be possible to expand the criteria for curative ESD of SM-GCs. We recognize the need to establish our findings in a larger patient population and by prospective study.

Acknowledgments This work was supported in part by a Grant-inAid for Scientific Research (C) (No. 23591021).

\section{References}

1. Japanese Gastric Cancer Association. Japanese classification of gastric carcinoma: 3rd English edition. Gastric Cancer. 2011;14: 101-12.

2. Oka S, Tanaka S, Kaneko I, Mouri R, Hirata M, Kawamura T, et al. Advantage of endoscopic submucosal dissection compared with EMR for early gastric cancer. Gastrointest Endosc. 2006;64: 877-83.

3. Ono H, Kondo H, Gotoda T, Shirao K, Yamaguchi H, Saito D, et al. Endoscopic mucosal resection for treatment of early gastric cancer. Gut. 2001;48:225-9.

4. Miyamoto S, Muto M, Hamamoto Y, Boku N, Ohtsu A, Baba S, et al. A new technique for endoscopic mucosal resection with an insulated-tip electrosurgical knife improves the completeness of resection of intramucosal gastric neoplasms. Gastrointest Endosc. 2002;55:576-81.

5. Probst A, Pommer B, Golger D, Anthuber M, Arnholdt H, Messmann H. Endoscopic submucosal dissection in gastric neoplasia-experience from a European center. Endoscopy. 2010; 42:1037-44.

6. Imagawa A, Okada H, Kawahara Y, Takenaka R, Kato J, Kawamoto $\mathrm{H}$, et al. Endoscopic submucosal dissection for early gastric cancer: results and degrees of technical difficulty as well as success. Endoscopy. 2006;38:987-90.

7. Gotoda T, Yanagisawa A, Sasako M, Ono H, Nakanishi Y, Shimoda $\mathrm{T}$, et al. Incidence of lymph node metastasis from early gastric cancer: estimation with a large number of cases at two large centers. Gastric Cancer. 2000;3:219-25.

8. Japanese Gastric Cancer Association. Japanese gastric cancer treatment guidelines 2010 (ver. 3). Gastric cancer. 2011;14: $113-23$

9. Kunisaki C, Akiyama H, Nomura M, Matsuda G, Otsuka Y, Ono $\mathrm{HA}$, et al. Lymph node status in patients with submucosal gastric cancer. Ann Surg Oncol. 2006;13:1364-71.
10. Goto O, Fujishiro M, Kodashima S, Ono S, Omata M. Outcomes of endoscopic submucosal dissection for early gastric cancer with special reference to validation for curability criteria. Endoscopy. 2009;41:118-22.

11. Gotoda T, Iwasaki M, Kusano C, Seewald S, Oda I. Endoscopic resection of early gastric cancer treated by guideline and expanded National Cancer Centre criteria. Br J Surg. 2010;97: 868-71.

12. Uedo N, Iishi $\mathrm{H}$, Tatsuta $\mathrm{M}$, Ishihara R, Higashino $\mathrm{K}$, Takeuchi $\mathrm{Y}$, et al. Long term outcomes after endoscopic mucosal resection for early gastric cancer. Gastric Cancer. 2006;9:88-92.

13. Oda I, Saito D, Tada M, Iishi H, Tanabe S, Oyama T, et al. A multicenter retrospective study of endoscopic resection for early gastric cancer. Gastric Cancer. 2006;9:262-70.

14. Isomoto H, Shikuwa S, Yamaguchi N, Fukuda E, Ikeda K, Nishiyama $\mathrm{H}$, et al. Endoscopic submucosal dissection for early gastric cancer: a large-scale feasibility study. Gut. 2009;58: 331-6.

15. Chung IK, Lee JH, Lee SH, Kim SJ, Cho JY, Cho WY, et al. Therapeutic outcomes in 1000 cases of endoscopic submucosal dissection for early gastric neoplasms: Korean ESD Study Group multicenter study. Gastrointest Endosc. 2009;69:1228-35.

16. Kang HJ, Kim DH, Jeon TY, Lee SH, Shin N, Chae SH, et al. Lymph node metastasis from intestinal-type early gastric cancer: experience in a single institution and reassessment of the extended criteria for endoscopic submucosal dissection. Gastrointest Endosc. 2010;72:508-15.

17. Hoteya S, Yamashita S, Kikuchi D, Nakamura M, Fujimoto A, Matsui A, et al. Endoscopic submucosal dissection for submucosal invasive gastric cancer and curability criteria. Dig Endosc. 2011;23:30-6.

18. Higashiyama M, Oka S, Tanaka S, Sanomura Y, Imagawa H, Shishido $\mathrm{T}$ et al. Risk factors for bleeding after endoscopic submucosal dissection of gastric epithelial neoplasm. Dig Endosc 2011 (in press).

19. Goto O, Fujishiro M, Kodashima S, Ono S, Niimi K, Hirano K, et al. A second-look endoscopy after endoscopic submucosal dissection for gastric epithelial neoplasm may be unnecessary: a retrospective analysis of postendoscopic submucosal dissection bleeding. Gastrointest Endosc. 2010;71:241-8.

20. Tajiri H, Kitano S. Complications associated with endoscopic mucosal resection: definition of bleeding that can be viewed as accidental. Dig Endosc. 2004;16(Suppl s1):S134-6.

21. Oka S, Tanaka S, Kaneko I, Mouri R, Hirata M, Kanao H, et al. Endoscopic submucosal dissection for residual/local recurrence of early gastric cancer after endoscopic mucosal resection. Endoscopy. 2006;38:996-1000.

22. Nakahara K, Tsuruta O, Tateishi H, Watanabe Y, Tamiya Y, Serikawa O, et al. Radiological diagnosis of the depressed type of gastric submucosal cancer without fold convergence-based on the vertical invasive depth of a differentiated-type submucosal cancer. Stomach and Intestine. 2007;42:25-38. (in Japanese with English abstract).

23. Isobe $\mathrm{S}$, Yoshino $\mathrm{J}$, Inui $\mathrm{K}$, Wakabayashi $\mathrm{T}$, Okushima $\mathrm{K}$, Kobayashi T, et al. Endosonographic diagnosis of the depth of cancerous invasive of differentiated type gastric cancer (in Japanese with English abstract). Stomach and Intestine. 2007;42: $79-87$.

24. Mouri R, Yoshida S, Tanaka S, Oka S, Yoshihara M, Chayama K. Usefulness of endoscopic ultrasonography in determining the depth of invasion and indication for endoscopic treatment of early gastric cancer. J Clin Gastroenterol. 2009;43:318-22.

25. Onogawa S, Kitadai Y, Amioka T, Kodama M, Cho S, Kuroda T, et al. Expression of vascular endothelial growth factor (VEGF)-C and VEGF-D in early gastric carcinoma: correlation with clinicopathological parameters. Cancer Lett. 2005;226:85-90. 
26. Park YD, Chung YJ, Chung HY, Yu W, Bae HI, Jeon SW, et al. Factors related to lymph node metastasis and the feasibility of endoscopic mucosal resection for treating poorly differentiated adenocarcinoma of the stomach. Endoscopy. 2008;40:7-10.

27. Hirasawa T, Gotoda T, Miyata S, Kato Y, Shimoda T, Taniguchi $\mathrm{H}$, et al. Incidence of lymph node metastasis and the feasibility of endoscopic resection for undifferentiated-type early gastric cancer. Gastric Cancer. 2009;12:148-52.

28. Son HJ, Song SY, Kim S, Noh JH, Sohn TS, Kim DS, et al. Characteristics of submucosal gastric carcinoma with lymph node metastatic disease. Histopathology. 2005;46:158-65.

29. Nonaka S, Oda I, Nakaya T, Kusano C, Suzuki H, Yoshinaga S, et al. Clinical impact of a strategy involving endoscopic submucosal dissection for early gastric cancer: determining the optimal pathway. Gastric Cancer. 2011;14:56-62.
30. Nishida T, Tanaka S, Haruma K, Yoshihara M, Sumii K, Kajiyama G. Histologic grade and cellular proliferation at the deepest invasive portion correlate with the high malignancy of submucosal invasive gastric carcinoma. Oncology. 1995;52: $340-6$.

31. Hanaoka N, Tanabe S, Mikami T, Okayasu I, Saigenji K. Mixedhistologic-type submucosal invasive gastric cancer as a risk factor for lymph node metastasis: feasibility of endoscopic submucosal dissection. Endoscopy. 2009;41:427-32.

32. Sanomura Y, Oka S, Tanaka S, Higashiyama M, Yoshida S, Arihiro K, et al. Predicting the absence of lymph node metastasis of submucosal invasive gastric cancer: expansion of the criteria for curative endoscopic resection. Scand J Gastroenterol. 2010; 45:1480-7. 